\begin{tabular}{|c|c|c|}
\hline \multirow{3}{*}{$\begin{array}{r}\text { Case Reports in } \\
\text { Gastroenterology }\end{array}$} & \multirow{2}{*}{\multicolumn{2}{|c|}{ Case Rep Gastroenterol 2015;9:56-61 }} \\
\hline & & \\
\hline & $\begin{array}{l}\text { DOI: } 10.1159 / 000377623 \\
\text { Publisned onine: February 12, } 2015\end{array}$ & $\begin{array}{l}\text { (c) } 2015 \text { S. Karger AG, Basel } \\
\text { 1662-0631/15/0091-0056 } \$ 39.50 / 0 \\
\text { www.karger.com/crg }\end{array}$ \\
\hline & \multicolumn{2}{|c|}{$\begin{array}{l}\text { This is an Open Access article licensed under the terms of the Creative Common } \\
\text { Attribution-NonCommercial } 3.0 \text { Unported license (CC BY-NC) (www.karger.com/OA } \\
\text { license), applicable to the online version of the article only. Distribution permitted for non } \\
\text { commercial purposes only. }\end{array}$} \\
\hline
\end{tabular}

\title{
The Diagnostic Challenges of Autoimmune Pancreatitis
}

\author{
Kata Papp ${ }^{a}$ Eliane Angst ${ }^{a, d} \quad$ Stefan Seidel $^{b} \quad$ Renata Flury-Frei ${ }^{c}$ \\ Franc Heinrich Hetzer ${ }^{a}$ \\ Clinics of a Surgery and Orthopedics and ${ }^{b}$ Radiology, Cantonal Hospital Schaffhausen, \\ Schaffhausen, 'Department of Pathology, Cantonal Hospital Winterthur, Winterthur, and \\ ${ }^{\mathrm{d}}$ Department of Visceral Surgery and Medicine, Inselspital, University of Bern, Bern, \\ Switzerland
}

\section{Key Words}

Autoimmune pancreatitis · Immunoglobulin G4 · Pancreatic cancer

\begin{abstract}
Autoimmune pancreatitis is a rare but important differential diagnosis from pancreatic cancer. This autoimmune disease can mimic pancreatic cancer by its clinical symptoms, including weight loss and jaundice. Furthermore imaging findings may include a mass of the pancreas. Here we present the case of a 67-year-old male patient diagnosed with autoimmune pancreatitis but showing the well-known symptoms of pancreatic cancer. This emphasizes the difficulties of histological findings and the importance of the correct diagnostic process.
\end{abstract}

(c) 2015 S. Karger AG, Basel

\section{Introduction}

Autoimmune pancreatitis is rare and appears in two different clinical entities, which are mainly differentiated by histological features. Type 1 autoimmune pancreatitis belongs to the immunoglobulin G4 (IgG4)-related diseases which are immune-mediated and share clinical, pathological and serological features. These include the tumor-like enlargement of the involved organs, an inflammatory infiltration by lymphoplasmacytic cells with a predominance of IgG4-positive plasma cells, venulitis, extended sclerosis and fibrosis [1]. Elevated serum levels of IgG4 are present in $60-70 \%$ of patients with IgG4-related disease [2]. Predominantly male patients in the sixth decade are affected by this type of autoimmune pancreatitis. Treatment with glucocorticoids is most often effective and the clinical response to 
Papp et al.: The Diagnostic Challenges of Autoimmune Pancreatitis

this treatment is a diagnostic criterion [3]. Beside pancreas involvement the following conditions may be part of this systemic disease: extrahepatic bile duct stricture, sclerosing sialadenitis, orbital disease with enlargement of the lacrimal gland or orbital pseudotumors and retroperitoneal fibrosis.

In contrast, type 2 autoimmune pancreatitis does not belong to the IgG4-related diseases, affects younger patients in the fourth decade and is evenly distributed between genders. The histological features may include lymphoplasmacytic infiltrates, but these are mostly negative for IgG4 immunohistological staining. The characteristic histological feature is the infiltration by neutrophil granulocytes, sometimes being so dense to appear as microabscesses in ducts and lobuli. The granulocytic infiltration frequently involves and destroys the epithelium of the pancreatic ducts, thus called granulocyte epithelial lesions.

Both types of autoimmune pancreatitis may present with obstructive jaundice and the onset of a diabetic condition. The clinical picture of pain and elevation of serum amylase is rare. Here we report the case of a male patient with type 1 autoimmune pancreatitis with classical symptoms of pancreatic cancer, emphasizing the difficulties of the diagnostic process in such cases.

\section{Case Report}

A 67-year-old male patient presented with painless jaundice, dark-brown urine and acholic stools. The general practitioner had diagnosed onset of a diabetic condition with a $\mathrm{HbA} 1 \mathrm{c}$ of $8.5 \%$ and a weight loss of $4 \mathrm{~kg}$, corresponding to a weight loss of $5 \%$. His antecedent history showed prostate cancer treated by prostatectomy 6 years before and a malignant melanoma on his back 5 years before. Both malignant conditions were followed periodically and did not show any signs of recurrence. Furthermore the patient had had borreliosis 30 years earlier and polymyalgia rheumatica for 2 years. The latter had been treated with low-dose steroids for one and a half years. During the first 6 months, $5 \mathrm{mg}$ of prednisone was given daily, then prednisone was tapered to $2.5 \mathrm{mg}$ twice a week.

A CT scan showed a double duct sign without clear delineated tumor, no calcification of the pancreas nor infiltration of the vessels (fig. 1). A sonography was performed, which showed a mass of $15 \times 23 \mathrm{~mm}$ in the pancreatic head. Blood tests showed normal values of the tumor markers CEA $(2.4 \mu \mathrm{g} / \mathrm{l})$ and CA19-9 $(<3 \mathrm{kU} / \mathrm{l})$ as well as total bilirubin of $50 \mu \mathrm{mol} / \mathrm{l}$. Surgery was indicated since we suspected pancreatic cancer due to the clinical and radiological findings.

Infiltration of the mesocolic artery found during surgery made the planned Whipple procedure impossible. Biopsies were taken from the pancreatic head. A cholecystectomy and a biliodigestive anastomosis were performed. The histological results showed chronic inflammation with fibrosis and fat necrosis, but no signs of malignancy. After discussion of the case on a multidisciplinary tumor board, a secondary percutaneous biopsy was taken. This one showed chronic periductal inflammation with infiltration of plasma cells, sclerosis, venulitis, parenchymal atrophy (fig. 2, fig. 3a) and strong positive immunohistochemical staining for IgG4 (fig. 3a, b). This led to the diagnosis of type 1 autoimmune pancreatitis in the absence of granulocytic epithelial lesions.

We determined IgG4 in the serum, which was elevated $(3.4 \mathrm{~g} / \mathrm{l}$, normal range 0.03$2.01 \mathrm{~g} / \mathrm{l}$ ), although the other autoimmune rates (rheumatoid factors, antinuclear antibodies, c-ANCA, p-ANCA) were normal. A follow-up CT scan 6 weeks later showed a 15\% reduction in the craniocaudal dimension, resulting in a less prominent pancreas with inhomogeneous 
Papp et al.: The Diagnostic Challenges of Autoimmune Pancreatitis

alteration of the structure. Nevertheless, neither calcification nor tumor mass was found (fig. 4). As the patient was meanwhile asymptomatic, further steroid therapy was omitted.

\section{Discussion}

Sarles et al. [4] first suspected autoimmune pancreatitis in 1961 when they found an idiopathic chronic pancreatitis with hypergammaglobulinemia in a patient. Meanwhile two types of autoimmune pancreatitis have been described. Type 1 autoimmune pancreatitis is also referred to as IgG4-related disease [5].

Type 1 autoimmune pancreatitis occurs in the sixth decade in $80 \%$ of cases and is more common among men [3]. The clinical findings match those found in our patient (jaundice, new-onset diabetes, weight loss) and diffuse pancreatic enlargement with diffusely irregular pancreatic duct ('sausage-shaped pancreas') in the abdominal CT scan [2, 3]. The histological pattern found in the second biopsy was typical, showing lymphoplasmacytic sclerosing pancreatitis with periductal lymphoplasmacytic infiltrate, fibrosis, venulitis and an abundance of IgG4-positive plasma cells. Typically granulocytic epithelial lesions are absent $[3,6]$. The serum IgG4 level is elevated, and other organs may be involved (e.g. sialadenitis, cholangitis, retroperitoneal fibrosis, tubulointerstitial nephritis) [3].

The diagnosis of autoimmune pancreatitis is challenging due to its rare occurrence and its clinical similarity to pancreatic cancer. Several groups have published criteria to allow its diagnosis [7]. A Japanese Group used pancreatic imaging (diffuse or segmental narrowing of the main pancreatic duct with irregular wall and diffuse or localized enlargement of the pancreas), laboratory data (high serum $\gamma$-globulin and/or IgG, or the presence of autoantibodies, such as antinuclear antibodies and rheumatoid factor), histopathological findings of the pancreatic biopsy, endocrine and exocrine function of the pancreas, and the presence of other associated autoimmune disorders (sclerosing cholangitis, sclerosing sialadenitis or retroperitoneal fibrosis) [8]. A Korean group used pancreatic imaging (diffuse enlargement/ swelling of the pancreas), laboratory findings (elevated levels of IgG or detected autoantibodies), histopathological findings of the pancreatic biopsy and the response to steroid therapy [9]. The Mayo Clinic defined 'HISORt' for histology, imaging, serology, other organ involvement and response to corticosteroid therapy) [2]. The Verona group added to the mentioned criteria the association with autoimmune diseases (e.g. ulcerative colitis, Crohn's disease, Sjögren's syndrome, autoimmune thyroiditis) [10].

The diagnostic criteria are overlapping with those of pancreatic cancer; the clinical symptoms are typical of pancreatic cancer and may also mimic gallbladder cancer (jaundice, right upper abdominal discomfort, nausea, fatigue) [11]. The findings on imaging studies may be challenging because a pancreatic mass may show instead of the typical diffusely irregular pancreatic duct within a diffusely enlarged gland with diffuse rim enhancement [1]. Elevated IgG4 levels were thought to be a specific diagnostic tool for autoimmune pancreatitis, but some patients are seronegative and about $10 \%$ of patients are positive without having autoimmune pancreatitis, but with pancreatic cancer or cholangiocarcinoma $[12,13]$. On the other hand, the tumor marker CA19-9 was considered to be specific for pancreatic cancer, but in $47-73 \%$ of cases with autoimmune pancreatitis CA19-9 is elevated [7, 14]. Therefore no single diagnostic test is sensitive and specific enough for autoimmune pancreatitis; rather, all the criteria have to be evaluated together combined with the clinical answer to treatment.

The treatment of choice for autoimmune pancreatitis are steroids. After an initial higher dose for 2-4 weeks, the acute symptoms of jaundice regress, and the steroids may be re- 
Papp et al.: The Diagnostic Challenges of Autoimmune Pancreatitis

duced and discontinued [1]. Relapses, which are frequent in autoimmune pancreatitis, are treated by the same regimen [6].

\section{Conclusion}

With this case report we aim to emphasize the importance of the diagnostic process in autoimmune pancreatitis. Unfortunately only histology allows a definite diagnosis, and therefore a high level of suspicion is essential to avoid unnecessary surgery.

\section{Disclosure Statement}

The authors have no conflicts of interest to disclose.

\section{References}

1 O’Reilly DA, Malde DJ, Duncan T, Rao M, Filobbos R: Review of the diagnosis, classification and management of autoimmune pancreatitis. World J Gastrointest Pathophysiol 2014;5:71-81.

-2 Chari ST, Smyrk TC, Levy MJ, Topazian MD, Takahashi N, Zhang L, Clain JE, Pearson RK, Petersen BT, Vege SS, Farnell MB: Diagnosis of autoimmune pancreatitis: the Mayo Clinic experience. Clin Gastroenterol Hepatol 2006;4:1010-1016; quiz 934.

3 Park DH, Kim MH, Chari ST: Recent advances in autoimmune pancreatitis. Gut 2009;58:1680-1689.

-4 Sarles H, Sarles JC, Muratore R, Guien C: Chronic inflammatory sclerosis of the pancreas - an autonomous pancreatic disease? Am J Dig Dis 1961;6:688-698.

-5 Kamisawa T, Funata N, Hayashi Y, Eishi Y, Koike M, Tsuruta K, Okamoto A, Egawa N, Nakajima H: A new clinicopathological entity of IgG4-related autoimmune disease. J Gastroenterol 2003;38:982-984.

-6 Pezzilli R, Pagano N: Pathophysiology of autoimmune pancreatitis. World J Gastrointest Pathophysiol 2014;5:11-17.

7 Chatterjee S, Oppong KW, Scott JS, Jones DE, Charnley RM, Manas DM, Jaques BC, White SA, French JJ, Sen GS, Haugk B, Nayar MK: Autoimmune pancreatitis - diagnosis, management and longterm follow-up. J Gastrointestin Liver Dis 2014;23:179-185.

8 Okazaki K, Kawa S, Kamisawa T, Naruse S, Tanaka S, Nishimori I, Ohara H, Ito T, Kiriyama S, Inui K, Shimosegawa T, Koizumi M, Suda K, Shiratori K, Yamaguchi K, Yamaguchi T, Sugiyama M, Otsuki M: Clinical diagnostic criteria of autoimmune pancreatitis: revised proposal. J Gastroenterol 2006;41:626-631.

-9 Kim KP, Kim MH, Kim JC, Lee SS, Seo DW, Lee SK: Diagnostic criteria for autoimmune chronic pancreatitis revisited. World J Gastroenterol 2006;12:2487-2496.

10 Ikeura T, Manfredi R, Zamboni G, Negrelli R, Capelli P, Amodio A, Calio A, Colletta G, Gabbrielli A, Benini L, Okazaki K, Vantini I, Frulloni L: Application of international consensus diagnostic criteria to an Italian series of autoimmune pancreatitis. United European Gastroenterol J 2013;1:276-284.

11 Lee YS, Lee SH, Lee MG, Lee SJ, Hwang JH, Shin E, Lee YJ: Immunoglobulin G4-related disease mimicking unresectable gallbladder cancer. Gut Liver 2013;7:616-620.

$\$ 12$ Ghazale A, Chari ST, Smyrk TC, Levy MJ, Topazian MD, Takahashi N, Clain JE, Pearson RK, Pelaez-Luna M, Petersen BT, Vege SS, Farnell MB: Value of serum IgG4 in the diagnosis of autoimmune pancreatitis and in distinguishing it from pancreatic cancer. Am J Gastroenterol 2007;102:1646-1653.

13 Oseini AM, Chaiteerakij R, Shire AM, Ghazale A, Kaiya J, Moser CD, Aderca I, Mettler TA, Therneau TM, Zhang L, Takahashi N, Chari ST, Roberts LR: Utility of serum immunoglobulin G4 in distinguishing immunoglobulin G4-associated cholangitis from cholangiocarcinoma. Hepatology 2011;54:940-948.

14 Chari ST, Takahashi N, Levy MJ, Smyrk TC, Clain JE, Pearson RK, Petersen BT, Topazian MA, Vege SS: A diagnostic strategy to distinguish autoimmune pancreatitis from pancreatic cancer. Clin Gastroenterol Hepatol 2009;7:1097-1103. 


\begin{tabular}{rl|l} 
Case Reports in & \multicolumn{2}{l}{} \\
\cline { 2 - 3 } Gastroenterology & Case Rep Gastroenterol 2015;9:56-61 & $\begin{array}{l}\text { ○ 2015 S. Karger AG, Basel } \\
\text { www.karger.com/crg }\end{array}$ \\
\cline { 2 - 3 } & &
\end{tabular}

Papp et al:: The Diagnostic Challenges of Autoimmune Pancreatitis

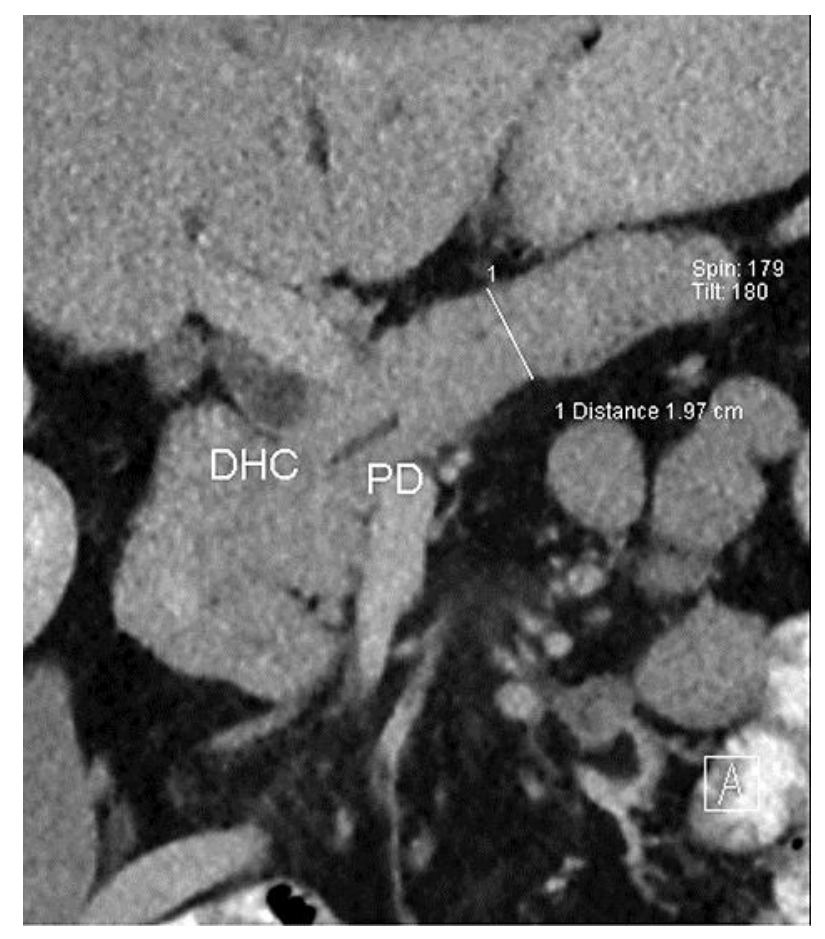

Fig. 1. CT scan showing the typical enlarged $(1.97 \mathrm{~cm})$ 'sausage-shaped' pancreas and a double duct sign. $\mathrm{DHC}=$ Common bile duct; $\mathrm{PD}=$ pancreatic duct.

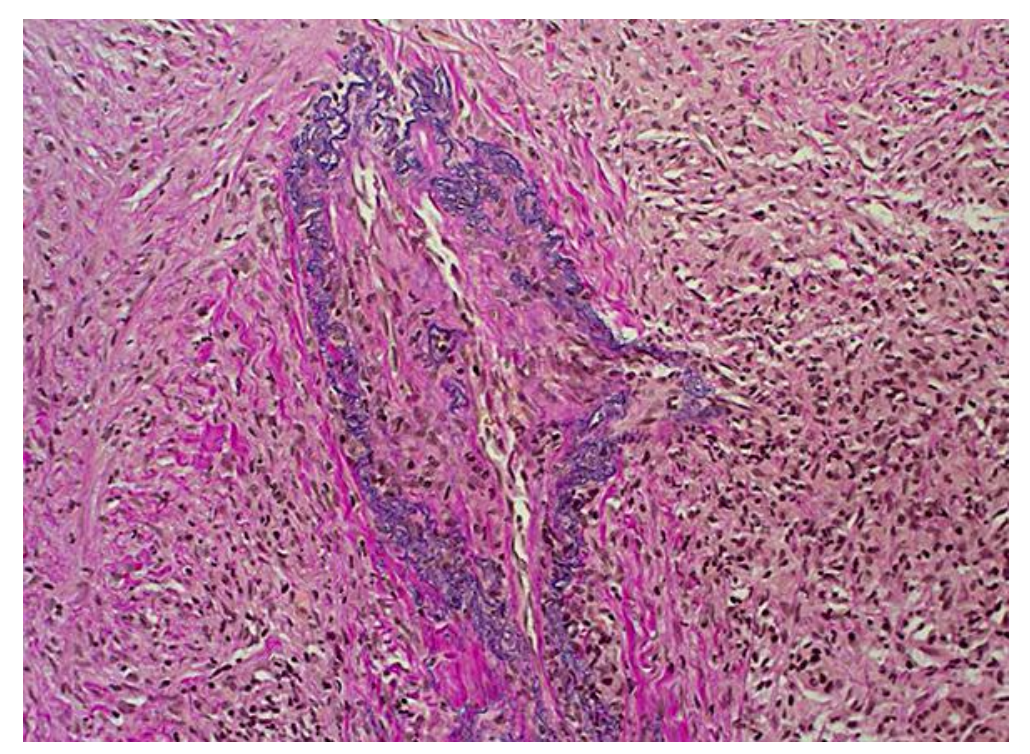

Fig. 2. Photomicrograph of elastica van Gieson staining showing chronic inflammation of the pancreas with sclerosis and parenchymal atrophy. Magnification $\times 400$. 


\begin{tabular}{ll|l} 
Case Reports in & \multicolumn{2}{l}{} \\
\cline { 2 - 3 } Gastroenterology & \multicolumn{2}{l}{ Case Rep Gastroenterol 2015;9:56-61 } \\
\cline { 2 - 3 } & DOI: 10.1159/000377623 & $\begin{array}{l}\text { @ 2015 S. Karger AG, Basel } \\
\text { www.karger.com/crg }\end{array}$ \\
\cline { 2 - 3 } & Papp et al.: The Diagnostic Challenges of Autoimmune Pancreatitis
\end{tabular}
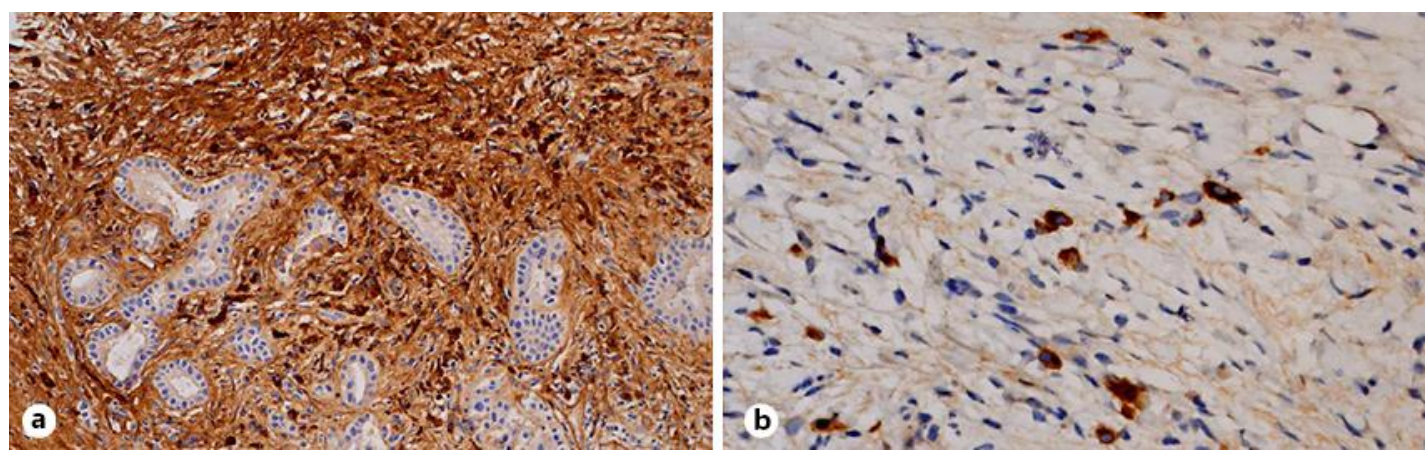

Fig. 3. Immunohistochemical staining for IgG4 showing numerous IgG4-positive plasma cells surrounding pancreatic hyperplastic ducts $(a$; magnification $\times 200)$ and single positive cells in chronic inflammation (b; magnification $\times 400)$.

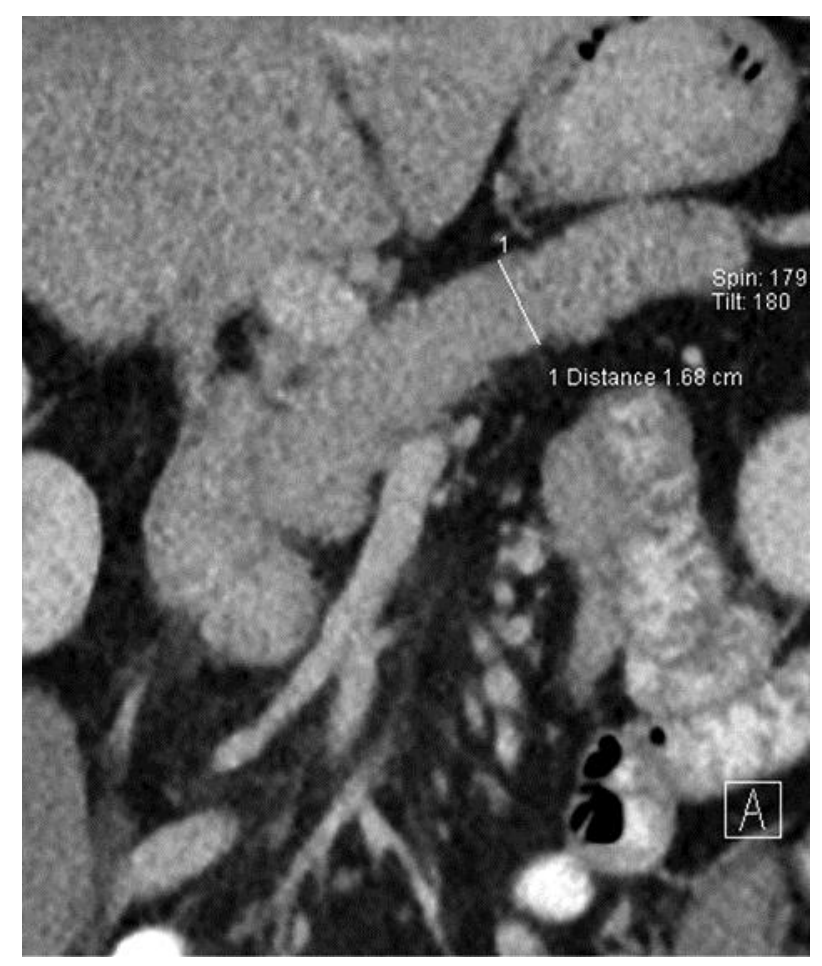

Fig. 4. CT scan showing a less prominent pancreas $(1.68 \mathrm{~cm})$ and resolution of bile duct dilation. 